\title{
Acute Kidney Injury (AKI) in the Setting of Multi-Organ Dysfunction Syndrome (MODS) Secondary to Yellow Fever Infection (YFI) in a 19-Year-Old Woman
}

\author{
Peter K. Uduagbamen ${ }^{1}$, Charles J. Elikwu ${ }^{2}$, Adesola T. Oyelese ${ }^{3}$, Marion I. Ogunmola1, \\ Tunde E. Thompson ${ }^{2}$, Tolulope E. Falana ${ }^{1}$ \\ ${ }^{1}$ Division of Nephrology and Hypertension, Department of Internal Medicine, Babcock University Teaching Hospital, \\ Ilishan-Remo, Nigeria \\ ${ }^{2}$ Department of Medical Microbiology, Babcock University Teaching Hospital, Ilishan-Remo, Nigeria \\ ${ }^{3}$ Department of Hematology, Babcock University Teaching Hospital, Ilishan-Remo, Nigeria \\ Email: ${ }^{\star}$ petr.uduagbamen@gmail.com
}

How to cite this paper: Uduagbamen, P.K., Elikwu, C.J., Oyelese, A.T., Ogunmola, M.I., Thompson, T.E. and Falana, T.E. (2020) Acute Kidney Injury (AKI) in the Setting of Multi-Organ Dysfunction Syndrome (MODS) Secondary to Yellow Fever Infection (YFI) in a 19-Year-Old Woman. Journal of Biosciences and Medicines, 8 , 142-148.

https://doi.org/10.4236/jbm.2020.89012

\section{Received: July 23, 2020}

Accepted: September 14, 2020

Published: September 17, 2020

\section{Copyright $\odot 2020$ by author(s) and} Scientific Research Publishing Inc. This work is licensed under the Creative Commons Attribution International License (CC BY 4.0).

http://creativecommons.org/licenses/by/4.0/

\section{(c) (i) Open Access}

\begin{abstract}
Background: Outbreak of yellow fever infection (YFI), a mosquito-borne disease, occurs sporadically worldwide especially in tropical nations. Acute kidney injury (AKI) commonly results from YFI and could be associated with a poor prognosis for victims even under intensive care unit (ICU). Pathophysiologic mechanisms for AKI include hypovolemic shut down, cytotoxicity, acute tubular necrosis (ATN), hemolysis, or coagulopathy. Early diagnosis, prompt and effective treatment modalities including dialysis improve treatment outcome. Aim: We report the case management of a 19-year-old woman who had yellow fever infection complicated by acute kidney injury in the setting of multi-organ dysfunction syndrome (MODS). Case Presentation: A 19-year-old woman who presented with fever, headache and vomiting for 2 weeks. In the course of the illness, urine volume became reduced and coke colored, followed by body swelling, yellowness of the eyes bleeding from the orifices. Examination revealed an acutely ill looking woman, icteric, and with pedal edema. Her pulse was 100/min and blood pressure was $120 / 80 \mathrm{mmHg}$. Liver was enlarged, soft and tender. She had proteinuria $3+$ and polymerase chain reaction (PCR) confirmed yellow fever infection. She had markedly deranged serum biochemical parameters for which she had a three-hour session of hemodialysis with Heparin anticoagulation. The urea reduction ratio (URR) was $46.9 \%$. Barrier nursing was commenced. She had 7 units of whole blood and a pint of fresh frozen plasma (FFP) with antibiotics, Rabeprazole, Tranexamic acid, Vitamin K and Frusemide. She had the second dialysis ses-
\end{abstract}


sion of HD and entered into the recovering phase of AKI and was subsequently discharged after 18th days on admission. Conclusion: Yellow fever infection occurs sporadically and could lead to MODS involving the kidneys, liver and hematologic system. Prompt initiation of dialysis, correction of coagulopathy, and antibiotics use are measures needed to arrest progression and death. Vaccination, destruction of the natural habitat of the carrier and infective organisms are necessary particularly in endemic regions of the world.

\section{Keywords}

Acute Kidney Injury, Acute Tubular Necrosis, Dialysis, Yellow Fever Virus, Fresh Frozen Plasma

\section{Introduction}

Yellow fever is a viral hemorrhagic fever (VHF) caused by yellow fever virus (YFV), of the Flavivirus genius and Flaviridale family that include other mosquito-borne infections caused by Dengue and Zika viruses [1]. Flaviviruses are enveloped, single-stranded RNA viruses transmitted by hematophagus arthropods and hosted by vertebrates mostly man and primates. Transmission is by urban, enzootic (sylvatic) cycle. First outbreak was in Cuba in 1646, in Nigeria, 1864 and has been reported in many countries particularly Angola and Brazil. Outbreaks in Nigeria are common between August and November due to surface waters, greater forests growth and less bush burning. Annually, about 20,000 individuals are affected worldwide with mortality up to $20 \%-50 \%$ in severe cases [2].

Organ system most commonly affected by YFV infection included the liver, kidneys, hematological, and gastrointestinal. It also commonly presents with multi-organ dysfunction syndrome (MODS) as in the index case. Mortality could be up to $20 \%-50 \%$ [2]. Prevention and vaccination remain the only means of curtailing disease at present [3].

Yellow fever virus infection has resulted in many fatalities in Nigeria usually from comorbidities and complications particularly those affecting the kidneys, liver and coagulopathy. Most deaths could have been averted (particularly those with AKI) with dialysis treatment. Studies on AKI from yellow fever infections are rare in our clime hence the need for this case report to highlight the need for prompt and effective treatment to reduce fatalities. A written informed consent was obtained from the patient for this publication.

\section{Case Report}

A 19-year-old female, presented with persistent fever, headache and vomiting for 2 weeks. Seven days into illness, she noticed coke colored urine, reduced urine volume, body swelling and yellowness of the eyes.

Examination: A young woman, acutely ill looking, icteric, with pedal edema. 
Her vitals were: pulse rate (PR)-100/min, blood pressure (BP)-120/80 $\mathrm{mmHg}$ and $26 / \mathrm{min}$. Liver was enlarged, soft, tender, and she had ascites.

Urinalysis showed: protein 3+, glucose $3+$.

Assessment: Acute kidney injury secondary to sepsis.

She had full systemic work up and investigation results showed markedly deranged serum electrolytes, urea, creatinine, markedly elevated liver enzymes and bilirubin and reduced albumin. She had the first hemodialysis (HD) session with Heparin $5000 \mathrm{IU}$ anticoagulation, blood flow rate (BFR) of $300 \mathrm{ml} / \mathrm{min}$ for 3 hours. The urea reduction ratio (URR) was $46.9 \%$.

Bleeding from the orifices was noticed six hours post dialysis, from intravenous sites, with epistaxis, hemoptysis, hematemesis and vagina. Clotting profile was deranged (beyond expected for dialysis anticoagulation) as shown in Table 1 \& Table 2. Further history revealed ingestion of "bush meat" (wild life animals like rabbit). The diagnosis was modified to:

Probable Viral Hemorrhagic Fever (VHF) complicated by acute kidney injury (AKI) and coagulopathy.

Barrier nursing was commenced. The Infection Prevention and Control (IPC) Team was called in, they instituted IPC measures that cover both standard and contact-based precautions. Blood samples were collected under strict aseptic condition, standard and VHF IPC measures. Blood sample was accorded the standard triple packaging and transported to Virology laboratory of the Lagos University Teaching Hospital, Lagos Nigeria. The result confirmed yellow fever infection.

She had 7 pints of whole blood and a pint of fresh frozen plasma (FFP) after Hematologist's review and bleeding stopped. Antibiotics, Rabeprazole, Tranexamic acid, Vitamin K and Frusemide were continued. She had the second session of $\mathrm{HD}$ and then entered the recovering phase of AKI with daily urine output of $>4 \mathrm{~L}$ which normalized at the end of the 2 nd week. She was discharged on

Table 1. Laboratory investigation results on admission and clinic follow up.

\begin{tabular}{|c|c|c|c|c|}
\hline Variables & Admission & Day 8 & Day 15 & 1st Clinic visit \\
\hline Packed cell volume ( $40 \%-52 \%)$ & 28 & 18 & 29.5 & 28 \\
\hline Mean corpuscular volume (76 - 96) & 72 & 60 & 64 & 62 \\
\hline White blood cell $\left(4-11 \times 10^{9}\right)$ & 4.3 & 3.7 & 3.1 & 4.8 \\
\hline Granulocytes $\left(2-7 \times 10^{9}\right)$ & 2.6 & 1.7 & 1.2 & 2.2 \\
\hline Lymphocytes $\left(1.5-4 \times 10^{9}\right)$ & 1.1 & 1.3 & 1.7 & 2.2 \\
\hline Platelets $\left(150-400 \times 10^{9}\right)$ & 64 & 88 & 180 & 163 \\
\hline Erythrocytes sedimentation rate $(<15 \mathrm{~mm} / \mathrm{Hr})$ & 102 & & & 22 \\
\hline Prothrombin time (12 - $14 \mathrm{~s})$ & 21 & 18 & & 15 \\
\hline International normalized ratio $(0.9-1.1)$ & 1.6 & 1.2 & & 1.0 \\
\hline Partial thromboplastin time (30 - $42 \mathrm{~s})$ & $>120$ & 50 & & 43 \\
\hline
\end{tabular}


Table 2. Laboratory results on admission and clinic follow up.

\begin{tabular}{|c|c|c|c|c|}
\hline Variables & Admission & Day 8 & Day 15 & Day 29 \\
\hline Sodium $(135-145 \mathrm{mmol} / \mathrm{l})$ & 135 & 139 & 139 & 139 \\
\hline Potassium $(3.5-5.0 \mathrm{mmol} / \mathrm{l})$ & 4.5 & 2.9 & 3.1 & 4.5 \\
\hline Chloride (97 - $107 \mathrm{mmol} / \mathrm{l})$ & 99 & 101 & 106 & 105 \\
\hline Bicarbonate $(22$ - $30 \mathrm{mmol} / \mathrm{l})$ & 18 & 21 & 23 & 28 \\
\hline Urea $(3-7 \mathrm{mmol} / \mathrm{l})$ & 32 & 10.4 & 3.9 & 2.9 \\
\hline Creatinine (50 - $110 \mathrm{umol} / \mathrm{l})$ & 877 & 194 & 83 & 59 \\
\hline Uric acid (mmol/l) & 631 & & 182 & 235 \\
\hline Alanine transaminase $(5-35 \mathrm{IU} / \mathrm{l})$ & 315 & & 72 & 49 \\
\hline Aspatate transaminase (5 - $40 \mathrm{IU} / \mathrm{l})$ & 227 & & 189 & 87 \\
\hline Gamma glutaryl transferase (7 - $45 \mathrm{IU} / \mathrm{l})$ & 827 & & 783 & 364 \\
\hline Alkaline phosphatase (50 - $125 \mathrm{IU} / \mathrm{l})$ & 850 & & 919 & 398 \\
\hline Total protein $(60-80 \mathrm{~g} / \mathrm{dl})$ & 73 & & & 58 \\
\hline Albumin $(35-55 \mathrm{~g} / \mathrm{dl})$ & 22 & & 31 & 24 \\
\hline Globulin $(25-35 \mathrm{~g} / \mathrm{dl})$ & 42 & & & 34 \\
\hline Total bilirubin $(1.7-20 \mathrm{umol} / \mathrm{l})$ & 191 & & 23.3 & 19.7 \\
\hline Conjugated bilirubin $(<5.1$ umol/l) & 21.8 & & & 8.6 \\
\hline Total cholesterol $(<5.2 \mathrm{mmol} / \mathrm{l})$ & 7.5 & & & 5.5 \\
\hline High density lipoprotein $(>1.3 \mathrm{mmol} / \mathrm{l})$ & 1.3 & & & 2.1 \\
\hline Low density lipoprotein $(<2.6 \mathrm{mmol} / \mathrm{l})$ & 4.9 & & & 3.0 \\
\hline Triglyceride $(1.7 \mathrm{mmol} / \mathrm{l})$ & 3.0 & & & 2.0 \\
\hline
\end{tabular}

the 18th day on admission and has remained stable in follow up visits. The care giver of the index patient (mother) received vaccination in the course of patient stay in our facility.

\section{Discussion}

We report a case of multi-organ dysfunction syndrome (with AKI, hepatotoxicity and coagulopathy) induced by yellow fever infection which occurred in a 19-year-old woman. The high mortality recorded in the past due to late diagnosis and management prompted us to institute an aggressive treatment modality of her condition considering the likely poor prognostic effects of combined renal, hepatic and clotting profile affectation.

The transmission of YFI can be by enzootic (sylvatic), intermediate (savannah) or urban. Mortality is often associated with MODS particularly hepato-renal disease [2]. Inoculation and viral release into blood stream follows a female mosquito bite. Viruses migrate through subcutaneous layer, lymph nodes 
(with replications), blood stream, to the liver, kidneys, heart, spleen [4] [5]. Cellular injury seen in severe forms of disease could be from viral toxicity, coagulopathy, vascular damage/leakage and shock. Endothelial injury with dysregulated coagulation is the primary pathologic pathway to MODS [6]. Genetic variants conferring some immunity on host is suggested though not authenticated.

Kidney damage results from vascular instability/leakage, shock and viral toxicity. ATN seen in the index patient could have resulted from bilirubin deposition, metabolism, epithelial cell obstruction or interlobular vessel thrombosis. Adrenal gland hemorrhage and necrosis could also cause AKI. Urine PH is low (increased tubular bicarbonate reabsorption) [7]. Non-fatal, progressive disease leads to interstitial fibrosis from interstitial necrosis, with edema, reperfusion injury, healing and interstitial scarring.

Diagnosis is by antigen detection (IgM) or IgG specific antibodies and confirmation by viral isolation. Molecular techniques like point of care (POC) and polymerase chain reactions (PCR) can be used. Index patient was diagnosed using a PCR-based screening test [8].

Treatment is by rehydration, blood transfusion, antibiotics, antipyretics and dialysis. Sofosbuvir, a direct antiviral inhibitor of RNA-directed RNA-polymerase-enzyme of hepatitis $C$ virus has been used with some improvement in clinical outcome [9]. Dialysis reduces cytokine production by viral antigens, the viral load and promotes homeostasis. It is improved with high flux dialyzers and high blood flow rates (BFR) as was done for the index patient who had a BFR of $300-350 \mathrm{ml} / \mathrm{min}$, even for the first session of HD. A set back of this dialysis protocol is increased risk of arrhythmias (from myocardial adrenergic over-activity, cytotoxicity, and the stress of the dialysis procedure), membrane instability, hypotension and hyperthermia which fortunately were not seen in this index case. Polyuria in AKI mostly indicates recovering of kidney function and could be associated with transient salt loosing state with marked reduction in levels of serum electrolytes. Though the index patient's polyuric phase was largely uneventful, however, when it does occur, management could be challenging as daily and at times twice daily serum electrolyte assessment could be needed and this could be difficult to meet in a low income setting. The Fresh frozen plasma (FFP) replaces plasma proteins, clotting factors and helps attenuates coagulopathy.

Prognosis is poor in MODS, coagulopathy and shock. Vaccination is with single dose, envelop-targeted YF-17D-vaccine [10]. The WHO's 10-year program "eliminate yellow fever epidemics" (EYE) in 2016 is expected to combat disease outbreak [4].

\section{Conclusion}

Yellow fever virus is a cause of VHF found sporadically in tropical regions of the world. It is commonly seen in the rainy season. The liver, kidney and coagulation pathways are commonly affected and usually carry worse prognosis. It also commonly presents with MODS requiring a multidisciplinary approach with 
rehydration, blood transfusion, control of secondary infections and dialysis. Dialysis, particularly in kidney affectation is very vital and gives dramatic improvement in treatment outcome. YFI could be fatal in MODS and hepato-renal disease. Large scale vaccination programs and vector eradication are the only means of combating disease. The observance of standard safety measures is also needed to reduce disease transmission.

\section{Acknowledgements}

The nurses and supporting staff of the female medical ward in Babcock University Teaching Hospital (BUTH).

\section{Conflicts of Interest}

The authors declare no conflicts of interest regarding the publication of this paper.

\section{References}

[1] Aubry, F., Nougairède, A., Gould, E.A., et al. (2015) Flavivirus Reverse Genetic Systems, Construction Techniques and Applications: A Historical Perspective. Antiviral Research, 114, 67-85. https://doi.org/10.1016/j.antiviral.2014.12.007

[2] Tomori, O. (2002) Yellow Fever in Africa: Public Health Impact and Prospects for Control in the 21st Century. Biomedica, 22, 178-210.

https://doi.org/10.7705/biomedica.v22i2.1157

[3] Hanley, K.A., Monath, T.P., Weaver, S.C., et al. (2013) Fever Versus Fever: The Role of Host and Vector Susceptibility and Interspecific Competition in Shaping the Current and Future Distributions of the Sylvatic Cycles of Dengue Virus and Yellow Fever Virus. Infection, Genetics and Evolution, 19, 292-311.

https://doi.org/10.1016/j.meegid.2013.03.008

[4] Chippaux, J.P. and Chippaux, A. (2018) Yellow Fever in Africa and the Americas: A Historical and Epidemiological Perspective. Journal of Venomous Animals and Toxins including Tropical Diseases, 24, Article Number: 20. https://doi.org/10.1186/s40409-018-0162-y

[5] Wu, W., Wang, J., Yu, N., et al. (2018) Development of Multiplex Real-Time Reverse-Transcriptase Polymerase Chain Reaction Assay for Simultaneous Detection of Zika, Dengue, Yellow Fever, and Chikungunya Viruses in a Single Tube. Journal of Medical Virology, 90, 1681-1686. https://doi.org/10.1002/jmv.25253

[6] Fernandez-Garcia, M.D., Meertens, L., Chazal, M., et al. (2016) Vaccine and Wild-Type Strains of Yellow Fever Virus Engage Distinct Entry Mechanisms and Differentially Stimulate Antiviral Immune Responses. MBio, 7, e01956-15. https://doi.org/10.1128/mBio.01956-15

[7] Monath, T.P. and Vasconcelos, P.F. (2015) Yellow Fever. Journal of Clinical Virology, 64, 160-173. https://doi.org/10.1016/j.jcv.2014.08.030

[8] Domingo, C., Charrel, R.N., Schmidt-Chanasit, J., et al. (2018) Yellow Fever in the Diagnostics Laboratory. Emerging Microbes \& Infections, 7, 129. https://doi.org/10.1038/s41426-018-0128-8

[9] Freitas, C.S., Higa, L.M., Sacramento, C.Q., et al. (2019) Yellow Fever Virus Is Susceptible to Sofosbuvir Both In Vitro and In Vivo. PLOS Neglected Tropical Diseases, 13, e0007072. https://doi.org/10.1371/journal.pntd.0007072 
[10] Shearer, F.M., Moyes, C.L., Pigott, D.M., et al. (2017) Global Yellow Fever Vaccination Coverage from 1970 to 2016: An Adjusted Retrospective Analysis. Lancet Infectious Diseases, 17, 1209-1217. https://doi.org/10.1016/S1473-3099(17)30419-X 